\section{Attitudes and the experience of integration}

\section{Anastasia Vlachou}

\author{
Research Student \\ Department of Education \\ University of Sheffield
}

\begin{abstract}
This paper is an attempt to raise awareness to attitudinal research regarding integration by highlighting some of the "less visible" factors that may influence teachers' attitudes towards the integration of students with Down's syndrome. I make no claims for the general application or representativeness of the statements, but I will claim that the following analysis will raise some challenging issues for further thinking.
\end{abstract}

For further information the author can be contacted at the following address: University of Sheffield, Department of Education, 388 Glossop Str., Sheffield, UK.

(C) 1993,1999. The Down Syndrome Educational Trust Down Syndrome Research and Practice 1993, 1 (2) 75-79

\section{Introduction}

It has been reported that integration requires change, creates discomfort and involves a considerable challenge to those whose careers, work and social relationships reinforce a segregated system. It would be naive to believe that integration policy will happen as part of a natural evolution in attitudes towards students with special needs.

Attitudinal research is based on the assumption that the attitudes expressed by people involved with children with special needs influence the way they behave towards them. Positive attitudes on the part of school personnel have frequently been identified as a crucial factor in the success of mainstreaming programmes (Jones, 1990; Thomas, 1985; Descent, 1987; Ward and Center, 1987; Szaday et al., 1989; Clough and Lindsay, 1991)

As Gottlieb and Siperstein (1976) have pinpointed, attitudes towards students with difficulties have always influenced the way they have been treated by society. For this reason studies assessing the attitudes of various groups are important in examining the teaching-learning process and the "delivery" of education in the classroom. The creation of a positive accepting environment and positive attitudes from teachers and peers, who are considered to be the significant others in someone's life, are some of the critical factors that facilitate integration. Mainstream teachers, along with parents, are central in providing the majority of time and learning support to children with special educational needs.

The attitudes of peers are equally important. The physical inclusion of students with special educational needs in the ordinary school community is the initial step, necessary but not sufficient for their social inclusion and academic development. The social gains, including the development of their personal identity, learning to make relationships, and developing a system of preparation for life in the community after school (Hellier, 1988), are the most important ones for children with disabilities. The achievement of such gains cannot take place without interaction with peers. In a mutual way integration enhances peers' knowledge, personal development and the quality of their interpersonal skills.

There is a general feeling among professionals in the field that in order to obtain gains by integrating students with disabilities we must improve attitudes towards them. However as Gottlieb et al. (1976) state:

before we are able to improve attitudes we must first acquire some adequate descriptors of what they are and why (p. 386).

Gottlieb et al. (1976) go further by stating that: one reason why we study attitudes towards mentally retarded [sic] people is to provide necessary information for planning social policy (p. 380).

A second reason is that by analysing attitudes there is an increasing awareness and understanding of the ideologies that underpin them. This knowledge is necessary as integration is "a commitment that requires knowledge, power, and participation" (Booth and Stathan, 1982a). If attitudes are related to the social and organisational context of the school community, this will enable us to clarify factors that function as obstacles to the implementation of the integration principle; and hence to identify ways of modifying school practices. 
Approaching the exploration of attitudes from this perspective gives rise to a different ethical and conceptual definition of integration, consequently to different kinds of questions. Firstly, instead of seeking the factors that influence attitudes solely within the individual, we extend our scope to the social environment in which the individual develops his/her attitudes.

Secondly we become more critical of the way disability research has been conducted. As a disabled writer Finkelstein (1980) has emphasised:

The predominant focus of attitude research has a natural expression one side of the disability relationship, being toward the disabled person ...by using the disabled person as the point of reference (In Oliver, 1987, p.10).

Thus there is a need to focus on the interaction between disabled students and their school environment, and on the ways in which the educational system should be constructed and organised in order to guarantee one of the most fundamental rights of its citizens: to be educated.

The purpose of this paper is to present some of the factors that influence teachers' attitudes towards the integration of students with Down's syndrome. It traces three main topics: support teachers, classroom organisation and sources of information. The idea underlying this paper is that the formation of attitudes is highly connected with specific aspects of the social environment in which these attitudes are being developed. Failure to take into consideration these aspects may have a negative impact on efforts to create a positive accepting environment.

\section{The Research}

This study - which is still in progress - is being carried out at a Yorkshire primary school that educates 340 students, including 30 students with varied special educational needs, six of whom have Down's syndrome. The participants in the study are: twenty five teachers - both mainstream and specials; a hundred and eighty mainstream students aged six to eleven years old, and twelve parents ( six mothers and six fathers) of students with Down's syndrome.

The methodological tools being used to conduct this study are intensive participant observations in classrooms where students with Down's syndrome are being educated, and semi-structured interviews with both teachers and parents. Role-playing and group discussions take place with mainstream students by using pictures and videotapes which present students with Down's syndrome in group situations in and out of the school community.

\section{The Teachers' Perspective}

In 1985 the Yorkshire school decided to implement a policy of integrating students with Down's syndrome and other special educational difficulties. In order to facilitate the implementation of integration the school hired seven teachers (either full or part time) to support mainstream teachers. Infant students with Down's syndrome were withdrawn from ordinary classes for half of the school day, while the rest of the time they were educated alongside their peers.

At the junior level students with Down's syndrome were educated in ordinary classes, being withdrawn when they had to go for speech therapy, when the support teacher felt that the students needed individual teaching approaches in small group situations, or when mainstream teachers felt that they could not incorporate students with Down's syndrome or other special needs in the academic tasks being assigned to the mainstream students.

The nineteen teachers who have already been interviewed admitted that they were quite apprehensive, if not negative, about educating students with Down's syndrome. They felt that they either did not know what was to be expected of them or that it was impossible for students with Down's syndrome to cope in ordinary classes.

The teachers' initial reaction is not a surprise if we consider that "people with Down's syndrome are subjected to two sets of prejudices; those concerned with their distinctive appearance and those about their relative incompetence ... they have been barred from schools because they "look handicapped". They have all been viewed as severely mentally handicapped despite a wide spread of abilities" (Booth, 1983, p.3)

The prevalent image fostered by some of the most authoritative and widely read sources in the field has been one which identifies the presence of Down's syndrome with severe mental handicap. Rynders et al. (1978) found that the educational capabilities of persons with Down's syndrome have been underestimated in the past because a large number of studies purporting to give an accurate picture of persons with Down's syndrome developmental capabilities have had serious methodological flaws (i.e. lack of confirmation of diagnosis, lack of reporting place of residence - home or institutions).

However, teachers' reservations can be linked with another factor that can be considered as a major positive step. Until recently it was thought that the only students who would benefit from inclusion in ordinary classes were those with moderate learning difficulties in reading and writing. More recently, however, there has been an integration of students with a much wider spectrum of strengths and weaknesses that at the beginning can be frightening for teachers, especially when misplaced viewpoints are the dominant information they receive.

Teachers' experience of educating students with Down's syndrome has contributed to the demystification of the syndrome. They became aware of the fact that individual differences exist in "Down's children" to the same extent that they exist in other children. Even if they categorised the students in question as "Down's syndrome" or "the specials", at the end of the day they interacted with them in respect of children's differences and particular needs. Assumptions such as "all Down's syndrome children are affectionate, exuberant, happy and musical" were considered by the teachers as lacking a basis in objective reality.

The issue of experience, however, is much more complicated. The same experiences that contribute to the demystification of the syndrome may reinforce negative feelings about the education of new students with Down's syndrome when the support provided for them is inadequate This is especially true of those mainstream teachers who believe that their priority is the education of mainstream students and the implementation of the National Curriculum; for them students with special needs are "extra work". This leads us to another 
issue: offering support to mainstream teachers.

\section{Support Teachers}

All the teachers interviewed stated that they were happy to include students with special needs in their classes as long as a support teacher was also in the class as well. If this was not the case then their attitudes towards integration turned out to be negative. They felt that the teacher - student ratio, the limited classroom space, the academic demands, the administrative work imposed on them by the introduction of the National Curriculum, the shrinkage of budgets given to schools, and the needs of the mainstream students already exceeded and overestimated teachers' human capabilities. They expressed the view that under such working conditions and with no support teachers, integration would have negative results for all the students. It was also observed by the researcher that on some days when a support teacher was not in school withdrawal of students with Down's syndrome reached the maximum point. Specifically, they were being integrated only for the morning story time, or for the time the students were drinking milk (duration of integration: 20 minutes).

It was also found that the quality of the relationship between the mainstream and support teacher influences both teachers' attitudes towards their jobs and responsibilities; this in turn influences the effectiveness of the support system and the quality of education that students receive.

In classes where a support teacher was mainly seen as teaching clearly identified children, either on a temporary withdrawal basis or alongside an ordinary class, responsibilities were clear cut with the danger of an internal classroom streaming between the "mainstreams" and the "specials".

In classes where students' education was perceived as the responsibility of both special and mainstream teachers boundaries were less clear. Both teachers were engaged in a mutual working situation by sharing advice, ideas and strategies for monitoring progress within the classroom context and for adapting the National Curriculum to students' needs. In such a situation students, regardless of their educational needs, were offered the choice and the flexibility of approaching both teachers at different times.

The way the two types of teacher perceive their responsibilities, and the working consensus they reach, influence the organisation and structure of the class. In turn, the classroom organisation influences students' perceptions, feelings, experiences and behaviour towards students with Down's syndrome or other educational difficulties.

\section{Classroom Organisation}

As Hargreaves (1972) has emphasised, the structure of their living accommodation has a striking impact on the friendship structure of the students. The way the class is organised can offer great opportunities for meaningful interaction between students with Down's syndrome and their peers. At the same time, however, it can offer opportunities for the marginalisation and devaluation of students who are different from the dominant norms. A stimulated environment is highly important for academic learning, but not enough for the development of interpersonal skills and social relationships between mainstream students and those with Down's syndrome.

Even though teachers believe that the playground and dining room are areas in which social integration can be effectively developed, it would be important to consider the possible relationship between these interactions and classroom practices. A further consideration relates to the fact that five out of six students with Down's syndrome being educated at the Yorkshire school were living a long way from their peers' neighbourhood.

The class is a "laboratory" for cultivating positive perceptions and co-operative working conditions. Fifteen out of the nineteen teachers interviewed stated that in their classes most of the students worked in groups. However, participant observations revealed a somewhat different picture. Most of the time students were working in groups but not as a group. It is significantly different to work as an individual with an individual task in front of you in a group than to work as a member of a group that shares a common goal.

Some of the teachers, being aware of the difference, introduced an activity day every week. That is , mixed ability groups of students worked together in order to accomplish a certain project which was rewarded by being presented at assembly. The working consensus under the such structured activities, with the teacher playing the role of facilitator, was observed as exhibiting mutual benefits for both mainstream students and those with Down's syndrome.

It was also observed that in situations such as the above a group environment was created by the students, in which distribution of roles and tasks, the sharing of ideas, and mutual help were the prevalent elements. Students with Down's syndrome were no different from any other students. When, in particular circumstances, their behaviour was unpredictable or negative to the work of the group as a whole, other students encouraged or helped them to accomplish the sub-task assigned to them.

Teachers frequently made group categorisations according to academic similarities. Different groups of students were assigned tasks at different levels. It is quite natural that categorisations should take place, as they help us to make sense of the information we receive. However, the process of categorisation itself, and the fixed assumptions, expectations and predictions that follow categorisation encompass the danger of stereotyping.

Even in mainstream schools a categorisation of students can lead to a highly structured streaming environment in which there is limited room for flexibility, acceptance and understanding. Through participant observations and discussions with teachers it was found that the teachers at the Yorkshire school had adopted different systems to avoid such streaming. Unfortunately, this did not always include students with special needs in all the classes. It was found that, while at the junior level all the students were sitting in mixed ability groups, at the infant level students with special needs comprised their own working group alongside the other groups. They were perceived as doing their own work with their own teacher. The younger the age and the greater the demands of the pupils reinforced teachers' attitudes towards such an organisation.

The issue of integration has often been presented in terms of a dualism: normality or abnormality, societal acceptance of differences or individual efforts to lean towards the norm, educational needs or special needs, disability or ability, and 
the compulsory (or non-compulsory) right to education in ordinary school. Teachers' attitudes towards one or the other perspective can be influenced by the sources from which they receive information and knowledge.

\section{Sources of information}

A knowledge of students' abilities can reduce prejudices and fears. A teacher will react differently when s/he is aware of the fact that students with Down's syndrome hold a higher comprehensive ability than an oral expressive ability, compared with a teacher who is not aware of it. Eight out of the nineteen teachers who were aware of this information stated that their main sources for it were their own experiences through trial and error. The integration process for them was a learning process as well. However, as a teacher strongly suggested, they should not be left alone to cope with a variety of situations without appropriate support.

Until recently most of the information revealed regarding the education of pupils with Down's syndrome originated solely from a medical model where the emphasis was on weaknesses, or from more general societal stereotypes. The emphasis on weaknesses created fears and in turn negative attitudes towards the integration of students with Down's syndrome. Teachers can be trapped in a vicious circle, as negative attitudes can be prejudices which perpetuate themselves by making interaction with students with Down's syndrome more difficult.

There is a need for a mechanism which will allow teachers to come together with other teachers from different schools, who may have more experience of educating students with Down's syndrome, in order to share anxieties, fears, ideas, and teaching-learning strategies.

There is also a need for more constructive interaction with the parents of students with Down's syndrome, as they experience their children's abilities and behaviour in varied and more authentic situations. Children exhibit different behaviour under different situations in different surroundings. It might be a common feeling among parents that their child behaves differently at home than when assessed by a psychologist. Conflict and frustration might arouse in parents attempt to communicate this difference to the psychologist.

The situation is not very different in a teacher-parent relationship. Teachers may feel that parents interfere with their jobs and perceive them as not capable or trustworthy in understanding the students they educate. Parents may feel that they lack the power of decision making in their child's educational programme. Additionally, conflict may arise between parents and teachers as a result of different understanding and expectations of integration. The base line, however, is the same. Both parents and teachers have a common aim: the creation of a pleasant and beneficial educational environment for the students. Even though the aim depends on the eye of the beholder the message is that parents need teachers' help as much as teachers need parents' help.

Twelve out if the nineteen teachers interviewed felt hesitant about the involvement of parents in the educational process in the classroom. A reason for this feeling was, as a teacher put it:

l'd like to be able to teach full stop, without having additional pressures from the government, from the media, from people outside telling me how to do things, that I am not doing it right.... I ought to change it. I really feel that we are getting a lot of outsiders telling us what to do, who aren't involved actually in education at our level. I really find that very hard indeed.

A deeper exploration showed that it was not towards parents' involvement that teachers were semi-negative but mainly towards the mounting pressures that they are under as a result of the introduction of the National Curriculum in the U.K.

Teachers felt that their main job was to teach the students and they found this even more difficult to do when they had to spend an enormous amount of time on administrative tasks, report writing and assessing students by tests which were often perceived by them as a waste of valuable teaching time. Additionally, they claimed that the context of the National Curriculum, and the policies for higher standards, did not take into consideration the fact that in every class there are students with special educational needs. Despite all the above complexities fifteen out of the nineteen teachers stated that they mainly endeavoured to fit the curriculum to the students' needs and not the opposite.

\section{Conclusion}

It seems that attitudes are closely connected with specific social environments and social directives. Efforts to change attitudes will come to nothing if the root causes of these attitudes are ignored. Through this research process has been realised that the term "attitudes", which is being used on an everyday basis, can be highly problematical, but highly significant as well for the implementation of integration. Often attitudes are being treated as existing somewhere at the sub-conscious level of the human being, and not as deep internalisations of social norms and cultural elements which are taken for granted. If one of the aims of integration is to work as a benefit and not as a cheap alternative to students' education, there is a need for further research in which the exploration of attitudes would not be insulated by issues such as governmental policies, societal norms, educational ethos and the individual's uniqueness.

\section{References}

Booth,T. and Stathan,J. (1982a) Parents' Choice: Establishing a Unit For Children With Down's Syndrome in an Ordinary School. London: Campaign for the Mentally Handicapped.

Booth,T. (1983) Integrating special education. In Booth, T. and Potts, $\mathrm{P}$ (Eds), Integrating Special Education, pp. 1-27. Oxford: Blackwell.

Clough,P. and Lindsay,G. (1991)Integration And The Support Service. Changing Roles In Special Education. NFERNELSON

Descent,T. (1987) Making The Ordinary School Special. London:Falmer Press

Gottlieb,J. and Siperstein,G.N. (1976) Attitudes towards mentally retarded persons: effects of attitude referent specificity. American Journal of Mental Deficiency, 80, 376387.

Hargreaves,H.D. (1972) Interpersonal Relations And Education. London:Routledge \& Kegan.

Hellier, C. (1988) Integration-a need for positive experience. Educational Psychology in Practise,4, 75-79.

Jones, N (1990) Special Educational Needs Review, Vol 3. London:Falmer Press.

Oliver, M. (1987) A challenge to research. Research Policy And Planning: Journal Of The Social Services Group,5,9-13. 


\title{
Teaching Miles in his first year in mainstream school
}

\section{Deborah Burbridge and Jacqueline Orchard}

\author{
Class Teacher and Special Needs Assistant \\ Arundel Court First and Nursery School, Portsmouth
}

\begin{abstract}
Miles is 6 years old. He has Down's syndrome and particularly severe dyspraxic problems which make learning to speak very difficult for him. With co-ordinated treatment of dyspraxia at home and school his speech is improving, but remains his greatest difficulty. His comprehension of speech has always been excellent for a child with Down's syndrome, and his teacher reports comprehension comparable with his peers in class. He learned Makaton from a young age and this is now supplemented by Bristol Sign Language, which his mother has learned at evening classes and teaches his Special Needs Assistant as necessary. Miles is good at making himself understood, using a combination of speech, sign and gesture, even to teachers and children without knowledge of sign language. Development of his expressive skills is a priority. Planning for the future includes development of his literacy and computer skills to support this expression, although recent improvements in his production of simple words are promising. Miles joined Arundel Court school in the nursery class at the age of 3.
\end{abstract}

The strategies employed in the teaching of Miles have been used to help us to achieve the overall aim of making him independent and to realise his own potential.

Miles is a member of a small class - originally 18, now 25 children - which has been a definite advantage.

$\mathrm{He}$ is included in all activities and class information lessons and is expected to follow the same instructions - reinforced by his SNA. He has individual attention from his SNA for most of the working day - 9am to $12 \mathrm{pm}$ and $1 \mathrm{pm}$ to $3 \mathrm{pm}$. This includes playtime but not lunchtime where he is supervised by the dinner staff. It is beneficial however, if at some time during the day, Miles works independently whilst his SNA either has her break or works with other children for a short while.

It is essential to have a planned timetable - ideally if the teacher, SNA and parent all contribute to the planning. The timetable is organised to cover different subjects and activities throughout the day. At the same time these must be flexible as Miles cannot always cope with a full day of structured activities. At times like this we allow him to choose what he would like to do and then go back to the planned activities later in the day. Theme/topic work is planned to cover several weeks - this provides familiarity and continued interest - often a topic will fire the imagination of the other children in the class and promotes a lot of discussion. Other areas of the curriculum are planned to achieve steady progress as a result of repetition and reinforcement at each stage.

We have found that the concept keyboard has been very successful with his reading and writing.

Generally we have found that Miles works better in a quiet area with which he is familiar. He responds well to a calm, disciplined situation not only when encouraging him to work but also when reprimanding him. At times he can be stubborn and refuses to complete work - we have found that work is usually completed if he is given the choice for the next activity! If however, he still refuses to co-operate then, as with other children, he has to work through part of a playtime or choosing activity - which usually focuses his concentration on completing the task very quickly!

At this stage we feel that Miles really benefits from being in a mainstream school - socially and academically. The children in his class have readily accepted him and do show a responsibility towards him. We have to monitor his whereabouts at all times and this is one of the responsibilities they have taken on board and share together with teaching staff. The role of SNA should be a person who can be firm and supportive and must have a good relationship with his/ her pupil, and if possible, with the parents.

We have found that home/school liaison is a very important factor when providing a concerted approach to learning both academically and socially. 